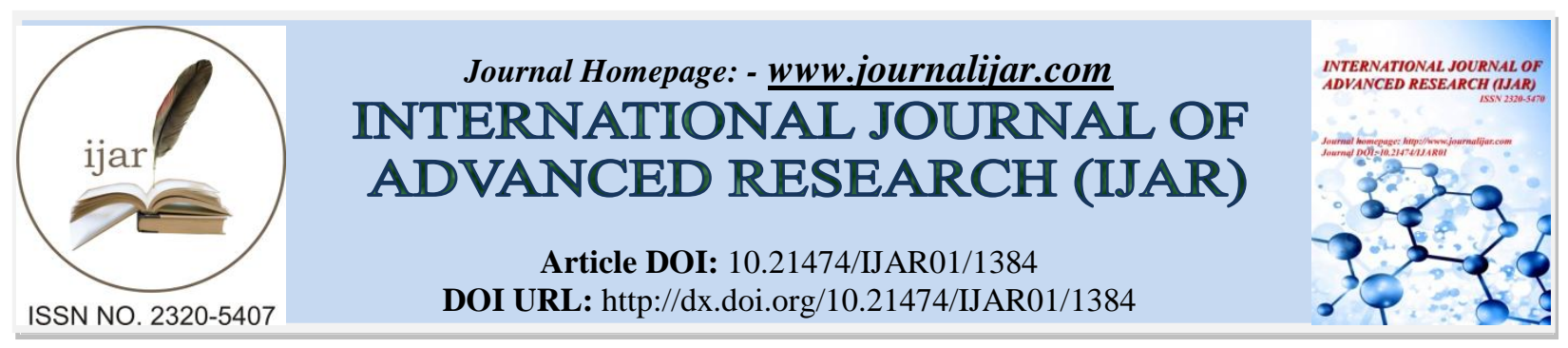

RESEARCH ARTICLE

\title{
A NOTE ON DEVELOPMENT OF METRIC FIXED POINT THEORY.
}

\author{
Suhas S. Patil ${ }^{1}$, U.P.Dolhare ${ }^{2}$ \\ Research Scholar, SRTMU Nanded (M.S), India, ${ }^{2}$ Associate Professor, Department of Mathematics, D.S.M. \\ College (M.S), India.
}

\section{Manuscript Info}

Manuscript History

Received: 12 June 2016

Final Accepted: 22 July 2016

Published: August 2016

\section{Abstract}

Metric Space, Contraction Mapping, Fixed Point, Banach Contraction principle

"In this Paper we develop some result by using fixed point theory. Also to prove these result we used Banach contraction mapping, contraction mapping principal and some Important result from beginning."

Copy Right, IJAR 2016., All rights reserved.

\section{Introduction:-}

Fixed point theory is one of the most fruitful \& powerful tools of modern mathematics and it may be a core subject of nonlinear analysis [1]. The presence or absence of fixed point is an intrinsic property of a function. However many necessary and sufficient conditions for the existence of such point involve a mixture of the algebraic order theoretic or topological properties of mapping or its domain [2].

Fixed point theory plays a very Important and significant role in analysis to solve differential equation, partial differential equations as well as random differential equation and integral equations. It is also useful in solving the Eigen value problems and for the characterization of the completeness of metric space.

Fixed point theory has some useful application in theory of games, non-linear problems in mechanics as well as in integral equation and topological dynamics, engineering mathematics, physics, economics, biology and chemistry.

\section{Preliminaries:-}

A point which is invariant or remains invariant under some transformation it undergoes then is called fixed point. In functional analysis fixed point theory is divided into three major areas [3]

1. Topological Fixed Point Theory

2. Metric Fixed Point Theory

3. Discrete Fixed Point Theory

4. Fuzzy Topological Fixed Point Theory

Historically the boundary lines between the four areas were defined by the discovery of three major theorems.

A. Brower's Fixed Point Theorem

B. Banach's Fixed Point Theorem 


\section{Tarski's Fixed Point Theorem}

The Banach contraction theorem is one of the most important and useful results in the metric fixed point theory. It is perhaps one of the most widely used fixed point theorem in all analysis. It is because the contraction condition on the mapping is simple and easy to verify, it requires only completeness assumption on the underlying metric space and so it finds almost canonical applications in the theory and differential and integral equations [3]. The basic idea was known to others earlier and the theorem first appeared in explicit form in the setting of C $[0,1]$ in Banach's 1922 PhD thesis[5].

Brower's perhaps in the first mathematician who introduce the fixed point theory in 1912 by proving, "If $\mathrm{C}$ be a unit ball in $\mathrm{E}^{\mathrm{n}}$ (Euclidean $\mathrm{n}$-dimensional space) and $\mathrm{T}: \mathrm{C} \rightarrow \mathrm{C}$ be a continuous mapping then $\mathrm{T}$ has a fixed point in $\mathrm{C}$.

$$
\text { i.e. } \mathrm{Tx}=\mathrm{x} \text { has a solution in } \mathrm{C}[4] \text {. }
$$

In 1922 Banach publish his fixed point theorem known as Banach Contraction Principle which uses the concept of Lipchitz's mapping.

\section{Definition:-}

1. Let $(M, d)$ be a metric space the map $T: M \rightarrow M$ is said to be

Lipchitz an if there exist a constant $\mathrm{k}>0$ (Called Lipchitz's constant)

Such that $\mathrm{d}(\mathrm{T}(\mathrm{x}), \mathrm{T}(\mathrm{y})) \leq \mathrm{kd}(\mathrm{x}, \mathrm{y})$ for all $\mathrm{x}, \mathrm{y} \in \mathrm{M}$

A Lipchitzan mapping with a Lipchitz constant $\mathrm{k}<1$ is called contraction.

\section{Remark:-}

1. a contraction mapping is always continuous

In 1922 Banach Contraction principle appeared and this was known for its simple and elegant proof by using Picard's iteration in a complete metric space.

\section{Theorem:-}

1. let $x$ be a complete metric space with $d$ and $f: X \rightarrow X$ is required to be Contraction. i.e. there must exists $\alpha<1$ such that

$$
\mathrm{d}(\mathrm{T}(\mathrm{x}), \mathrm{T}(\mathrm{y})) \leq \alpha \mathrm{d}(\mathrm{x}, \mathrm{y}) \text { for }
$$

all $\mathrm{x}, \mathrm{y}$ belongs to $\mathrm{X}$ so $\mathrm{f}$ has a fixed point in fact exactly one.

Proof:- let $\mathrm{x} \in \mathrm{X}$ be an arbitrary element starting from $\mathrm{x}$ we form the iteration.

$$
x_{1}=f x, x_{2}=f_{1}, x_{3}=f_{2}
$$

We verify that $\left\{x_{n}\right\}$ is a Cauchy sequence then we have

$\mathrm{d}\left(\mathrm{x}, \mathrm{x}_{2}\right)=\mathrm{d}\left(\mathrm{fx}, \mathrm{fx}_{1}\right) \leq \alpha \mathrm{d}\left(\mathrm{x}, \mathrm{x}_{1}\right)=\alpha \mathrm{d}(\mathrm{x}, \mathrm{f}(\mathrm{x}))$

$\mathrm{d}\left(\mathrm{x}_{2}, \mathrm{x}_{3}\right)=\mathrm{d}\left(\mathrm{fx}_{1}, \mathrm{fx}_{2}\right) \leq \alpha \mathrm{d}\left(\mathrm{x}, \mathrm{x}_{2}\right)=\alpha^{2} \mathrm{~d}(\mathrm{x}, \mathrm{f}(\mathrm{x}))$

$\mathrm{d}\left(\mathrm{x}_{3}, \mathrm{x}_{4}\right)=\mathrm{d}\left(\mathrm{fx}_{2}, \mathrm{fx}_{3}\right) \leq \alpha \mathrm{d}\left(\mathrm{x}_{2}, \mathrm{x}_{3}\right)=\alpha^{3} \mathrm{~d}(\mathrm{x}, \mathrm{f}(\mathrm{x}))$

In general for any positive integer $\mathrm{n}$,

$\mathrm{d}\left(\mathrm{x}_{\mathrm{n}}, \mathrm{x}_{\mathrm{n}+1}\right) \leq \alpha^{\mathrm{n}} \mathrm{d}(\mathrm{x}, \mathrm{f}(\mathrm{x}))$

Also for any positive integer $\mathrm{p}$

$d\left(x_{n}, x_{n+p}\right) \leq d\left(x_{n}, x_{n+1}\right)+d\left(x_{n+1}, x_{n+2}\right)+d\left(x_{n+p-1}, x_{n+p}\right)$

$\leq \alpha^{\mathrm{n}} d(\mathrm{x}, \mathrm{fx}) \leq \alpha^{\mathrm{n}+1} \mathrm{~d}(\mathrm{x}, \mathrm{fx})+-\cdot-\cdot-\alpha^{\mathrm{n}+\mathrm{p}-1} d(\mathrm{x}, \mathrm{f}(\mathrm{x}))$

$=\left(\alpha^{\mathrm{n}}+\alpha^{\mathrm{n}+1}+\alpha^{\mathrm{n}+\mathrm{p}-1}\right) \mathrm{d}(\mathrm{x}, \mathrm{f}(\mathrm{x}))$

$=\frac{\alpha^{n}-\alpha^{n+p}}{1-\alpha} \mathrm{d}(\mathrm{x}, \mathrm{f}(\mathrm{x}))<\frac{\alpha^{n}}{1-\alpha} \mathrm{d}(\mathrm{x}, \mathrm{f}(\mathrm{x})), \quad 0<\alpha<1$

Since for $\alpha<1$ the above relation show that $d\left(x_{n}, x_{n+p}\right) \rightarrow 0$ as $n \rightarrow \infty$

$\therefore\left\{x_{n}\right\}$ is a Cauchy sequence

$\therefore \mathrm{X}$ is complete. 
The sequence $\left\{x_{n}\right\}$ converges to a point $X_{0}$ in $X$.

Now, we have to show that $\mathrm{fx}_{0}=\mathrm{x}_{0}$ (Since we have to show that $\mathrm{fx}_{0}=\mathrm{x}_{0}$ )

$\mathrm{d}\left(\mathrm{fx}_{0}, \mathrm{fx}_{0}\right) \leq \mathrm{d}\left(\mathrm{x}_{0}, \mathrm{x}_{\mathrm{n}}\right)+\mathrm{d}\left(\mathrm{x}_{\mathrm{n}}, \mathrm{fx}_{0}\right)$

$$
\begin{gathered}
=d\left(x_{0}, x_{n}\right)+d\left(x_{n-1}, f_{0}\right) \\
\quad \leq d\left(x_{0}, x_{n}\right)+\alpha d\left(\underset{n-1}{x}, x_{0}\right) \underset{\quad x_{0}=x_{0},}{\longrightarrow} \text { as } n \rightarrow \infty
\end{gathered}
$$

Hence $x_{0}$ is a fixed point of $f$.

Also uniqueness can be easily check using contradiction method.

Therefore $\mathrm{f}$ has a unique fixed point in $\mathrm{X}$.

\section{Main Result:-}

Banach conraction Theorem:-

\section{Definition:-}

2. let $\mathrm{x}$ be any non-empty set and a mapping $\mathrm{T}: \mathrm{X} \rightarrow \mathrm{X}$ a point $\bar{x} \in \mathrm{X}$

Called a fixed point of $\mathrm{T}$ if $\mathrm{T}(\bar{x})=\bar{x}[3]$.

\section{Example:-}

1. let $X \in R$ be a nonempty set and a mapping $T: X \rightarrow X$ defined by

$\mathrm{T}(\mathrm{x})=\mathrm{x}+\mathrm{a}, \mathrm{a} \neq 0$ then $\mathrm{T}$ has no fixed point.

\section{Remark:-}

2. Above Ex.1 there is no any fixed point, it may have a unique fixed point, it may have more than one fixed point or even infinity may fixed point.

\section{Definition:-}

3. A Mapping $T: X \rightarrow X$ of the metric space $(x, d)$ is said to be Lipchitz

Continuous if there exist a constant $\alpha>0$ such that

$\mathrm{d}[\mathrm{T}(\mathrm{x}), \mathrm{T}(\mathrm{y})] \leq \alpha \mathrm{d}(\mathrm{x}, \mathrm{y})$ for all $\mathrm{x}, \mathrm{y} \in \mathrm{X}$

a) If $\alpha \in(0,1)$ then $\mathrm{T}$ is Called Contraction

b) If $\alpha=1$ then $\mathrm{T}$ is Called non-expensive

c) If $\mathrm{d}[\mathrm{T}(\mathrm{x}), \mathrm{T}(\mathrm{y})]<\mathrm{d}(\mathrm{x}, \mathrm{y})$ for all $\mathrm{x} \neq y$

Then $\mathrm{T}$ is Called Contractive.

Thus the no. $\alpha$ is called Lipchitz constant of T.

\section{Remark:-}

3. Every Lipchitz continuous function is continuous and every contraction

Mapping is contractive but converse is not true [3].

\section{Theorem (Banach Contraction Theorem):-}

Let $(\mathrm{x}, \mathrm{d})$ be a complete metric space and $\mathrm{T}: \mathrm{X} \longrightarrow \mathrm{X}$ be a contraction

Mapping, then $T$ has a unique fixed point.

Proof:- We have to construct a sequence $\left\{X_{n}\right\}$ by iterative method as following.

Let $\mathrm{X}_{0} \in \mathrm{X}$ be any arbitrary point, since $\mathrm{X}_{0} \neq \mathrm{T}\left(\mathrm{x}_{0}\right)$

Consider $X_{1}=T\left(x_{0}\right), X_{2}=T(x 1), X_{3}=T\left(x_{2}\right),-------X_{n}=T\left(x_{n-1}\right)$ for all $n \in N$. We say that this sequence $\left\{X_{n}\right\}$ of points of $\mathrm{X}$ is a Cauchy sequence.

Since $\mathrm{T}$ is a contraction mapping with Lipchitz constant

$$
\begin{aligned}
& 0<\alpha<1 \quad \text { for all } \mathrm{P}=1,2,----- \\
& \mathrm{d}\left(\mathrm{x}_{\mathrm{p}+1}, \mathrm{x}_{\mathrm{p}}\right)= \mathrm{d}\left[\mathrm{T}(\mathrm{x}), \mathrm{T}\left(\mathrm{x}_{\mathrm{p}-1}\right)\right] \leq \alpha \mathrm{d}\left(\mathrm{x}_{\mathrm{p}}, \mathrm{x}_{\mathrm{p}-1}\right) \\
&=\alpha \mathrm{d}\left[\mathrm{T}\left(\mathrm{x}_{\mathrm{p}-1}\right), \mathrm{T}\left(\mathrm{x}_{\mathrm{p}-2}\right)\right] \leq \alpha^{2} \mathrm{~d}\left(\mathrm{x}_{\mathrm{p}-1}, \mathrm{x}_{\mathrm{p}-2}\right) \\
&=-\alpha^{\mathrm{p}-1} \mathrm{~d}\left[\mathrm{~T}\left(\mathrm{x}_{1}\right), \mathrm{T}\left(\mathrm{x}_{0}\right)\right] \leq \alpha^{\mathrm{p}} \mathrm{d}\left(\mathrm{x}_{1}, \mathrm{x}_{0}\right)
\end{aligned}
$$

Let any positive integers $\mathrm{m}, \mathrm{n}$ such that $\mathrm{n}<\mathrm{m}$, then by triangle inequality we have, 


$$
\begin{gathered}
\mathrm{d}\left(\mathrm{x}_{\mathrm{m}}, \mathrm{x}_{\mathrm{p}}\right) \leq \mathrm{d}\left(\mathrm{x}_{\mathrm{m}}, \mathrm{x}_{\mathrm{m}-1}\right)+\mathrm{d}\left(\mathrm{x}_{\mathrm{m}-1}, \mathrm{x}_{\mathrm{m}-2}\right)+------+\mathrm{d}\left(\mathrm{x}_{\mathrm{n}+1}, \mathrm{x}_{\mathrm{n}}\right) \\
\leq\left(\alpha^{\mathrm{m}-1}+\alpha^{\mathrm{m}-2}+-----\alpha^{1}\right) \mathrm{d}\left(\mathrm{x}_{1}, \mathrm{x}_{0}\right) \\
\leq \alpha^{\mathrm{n}}\left(\alpha^{\mathrm{m}-\mathrm{n}-1}+\alpha^{\mathrm{m}-\mathrm{n}-2}+---------+1\right) \mathrm{d}\left(\mathrm{x}_{1,} \mathrm{x}_{0}\right) \\
\leq \frac{\alpha^{n}}{1-\alpha} \mathrm{d}\left(\mathrm{x}_{1}, \mathrm{x}_{0}\right)
\end{gathered}
$$

Since $\lim _{n \rightarrow 0}(\alpha)^{n}=0 \& \mathrm{~d}\left(\mathrm{x}, \mathrm{x}_{0}\right)$ is a fixed, as RHS of above equation come to 0 as $\mathrm{n}$ tends to $\infty$.

Hence it means that $\left\{X_{n}\right\}$ is a Cauchy sequence in $X$. so $X$ is complete there exists. $\bar{x} \in X$ such that $X_{n}$ tends to $\bar{x}$. And we show that this limit point $\bar{x}$ is a fixed point of $\mathrm{T}$.

Since $\mathrm{T}$ is a contraction mapping from the triangular inequality we have,

$$
\begin{aligned}
& \mathrm{d}(\bar{x}, \mathrm{~T}(\bar{x})) \leq \mathrm{d}\left(\bar{x}, \mathrm{x}_{\mathrm{n}}\right)+\mathrm{d}\left(\mathrm{x}_{\mathrm{n}}, \mathrm{T}(\bar{x})\right) \\
& =\mathrm{d}\left(\bar{x}, \mathrm{x}_{\mathrm{n}}\right)+\mathrm{d}\left(\mathrm{T}\left(\mathrm{x}_{\mathrm{n}-1}\right), \mathrm{T}(\bar{x})\right) \\
& \left.\leq \mathrm{d}\left(\bar{x}, \mathrm{x}_{\mathrm{n}}\right)+\alpha \mathrm{d}\left(\mathrm{x}_{\mathrm{n}-1}, \bar{x}\right)\right) \longrightarrow 0 \text { as } \mathrm{n} \longrightarrow \infty \\
& \text { Hence } \mathrm{d}\left(\mathrm{x}_{\mathrm{n}}, \mathrm{T}(\bar{x})\right)=0 \text { \& so } \mathrm{T}(\bar{x})=\bar{x} \text {. } \\
& \text { To show } \mathrm{T} \text { is unique fixed point. }
\end{aligned}
$$

Then $\mathrm{T}(\mathrm{X})=\mathrm{X}$ and $\mathrm{T}(\mathrm{Y})=\mathrm{Y}$. Since $\mathrm{T}$ is a contraction mapping we have

$\mathrm{d}(\mathrm{x}, \mathrm{y})=\mathrm{d}[\mathrm{T}(\mathrm{x}), \mathrm{T}(\mathrm{y})] \leq \mathrm{d}(\mathrm{x}, \mathrm{y})<\mathrm{d}(\mathrm{x}, y)$

Remark: -

which is a contraction, hence $\mathrm{x}=\mathrm{y}$.

4. In above theorem if $\mathrm{X}$ is not complete then $\mathrm{T}$ may not have a fixed point.

\section{Remark: -}

5. If $\mathrm{T}$ is not contraction in above theorem (2) then it may not have a fixed point.

\section{Theorem:-}

Let metric space $(\mathrm{x}, \mathrm{d})$ and $\mathrm{T}: \mathrm{X} \longrightarrow \mathrm{X}$ be a mapping such that for some integer $\mathrm{m}, \mathrm{T}^{\mathrm{m}}=\mathrm{T} 0 \mathrm{~T} 0 \ldots \ldots . .0 \mathrm{~T}$ is a contraction mapping, then $\mathrm{T}$ has a Unique fixed point.

Proof: - As per the above theorem [2] $\mathrm{T}^{\mathrm{m}}$ has a unique fixed point $\mathrm{x} \in \mathrm{X}$.

Such that $\mathrm{T}^{\mathrm{m}}(\mathrm{x})=\mathrm{x}$ then $\mathrm{T}(\mathrm{x})=\mathrm{T}\left[\mathrm{T}^{\mathrm{m}}(\mathrm{x})\right]=\mathrm{T}^{\mathrm{m}}(\mathrm{T}(\mathrm{x}))$

and so $\mathrm{T}(\mathrm{x})$ is a fixed point of $\mathrm{T}^{\mathrm{m}}$.

Since the fixed point of $\mathrm{T}^{\mathrm{m}}$ is a unique $\mathrm{T}(\mathrm{x})=\mathrm{x}$.

To prove the uniqueness we assume that $\mathrm{y}$ is another fixed point of $\mathrm{T}$, then

$\mathrm{T}(\mathrm{y})=\mathrm{y} \&$ therefore $\mathrm{T}^{\mathrm{m}}(\mathrm{y})=\mathrm{y}$

Again by the uniqueness of the fixed point of $\mathrm{T}^{\mathrm{m}}$, we have $\mathrm{x}=\mathrm{y}$.

Hence $x \in X$ is a unique fixed point of $T$.

\section{Theorem:-}

Let $(\mathrm{x}, \mathrm{d})$ be a compact metric space and $\mathrm{T}: \mathrm{X} \longrightarrow \mathrm{X}$ be a contractive mapping

then $\mathrm{T}$ has a unique fixed point $\bar{x}$. Moreover for any $\mathrm{x} \in \mathrm{X}$,

$\lim _{n \rightarrow \infty}(T)^{n}(x)=\bar{x}$ that is the successive iterates

$\mathrm{T}(\mathrm{x}) \mathrm{T}^{2}(\mathrm{x}) \ldots \ldots \ldots \mathrm{T}^{\mathrm{n}}(\mathrm{x}) \ldots \ldots .$. Converge to the unique fixed point $\bar{x}$ of $\mathrm{T}$.

Proof: - Define a mapping $: \mathrm{X} \longrightarrow \mathrm{R}_{+}$such that as $\varphi(x)=\mathrm{d}[\mathrm{x}, \mathrm{T}(\mathrm{x})]$ for all $\mathbf{x} \in \mathbf{X}$,

Then $\varphi$ is continuous. Indeed by contractiveness of $\mathrm{T}$, we have

$$
\begin{gathered}
|\varphi(x)-\varphi(y)|=|d(x, T(x))-d(y, T(y))| \\
\leq|d(x, T(x))-d(T(x), y)|+|d(T(x), y)-d(y, T(y))|
\end{gathered}
$$$$
\leq \mathrm{d}(\mathrm{x}, \mathrm{y})+\mathrm{d}(\mathrm{T}(\mathrm{x}), \mathrm{T}(\mathrm{y}))<2 \mathrm{~d}(\mathrm{x}, \mathrm{y}) \text {. }
$$

Let $\in>0$ be given, then $|\varphi(x)-\varphi(y)|<2 \mathrm{~d}(\mathrm{x}, \mathrm{y})<\epsilon$

Whenever $\mathrm{d}(\mathrm{x}, \mathrm{y})<\delta=\frac{\epsilon}{2}$

$\therefore$ T is continuous, hence $\varphi$ is bounded below. 
Since $\mathrm{X}$ is compact and $\varphi$ is continuous there exists a minimize $\bar{x} \in \mathrm{X}$ of $\varphi$

i.e. there exist $\bar{x} \in \mathrm{X}$ such that $\varphi(\bar{x}) \leq \varphi(y)$ for all $\mathrm{y} \in \mathrm{X}$

Conversely, we show that $\bar{x}$ is a fixed point of $\mathrm{T}$.

Suppose that $\bar{x}$ is not fixed point of $\mathrm{T} . \mathrm{T}(\bar{x}) \neq \bar{x}$

by contractiveness of $\mathrm{T}$, we have

$\varphi[T(\bar{x})]=d\left[T(\bar{x}), T^{2}(\bar{x})\right]<\mathrm{d}((\bar{x}), \mathrm{T}(\bar{x})]=\varphi(\bar{x})$

Which contracts that $(\bar{x})$ is a fixed point of $\mathrm{T}$. The uniqueness follows on the lines of the proof of theorem 2]

Let $\mathrm{x} \in \mathrm{X}$. If $\mathrm{T}^{\mathrm{n}}(\mathrm{x}) \neq \bar{x}$ then,

$\mathrm{d}\left[\mathrm{T}^{\mathrm{n}+1}(\mathrm{x}), x\right]=d\left[\mathrm{~T}^{\mathrm{n}+1}(\mathrm{x}), \mathrm{T}(\bar{x})\right]<d\left[\mathrm{~T}^{\mathrm{n}}(\mathrm{x}), \bar{x}\right]$ for all $\mathrm{n} \in \mathrm{N}$.

$d\left[\mathrm{~T}^{\mathrm{n}+1}(\mathrm{x}), \bar{x}\right]$ is a strictly decreasing sequence of nonnegative real number and so converges to its infimum.

Suppose that $\alpha=\lim _{n \rightarrow \infty} d\left[(T)^{n+1}(x), \bar{x}\right]$

Since $T^{n}(x)$ is a sequence of point of a compact metric space there exist a subsequence $T^{n k}(x)$ which converges to some point, say $\mathrm{y} \in \mathrm{X}$. since $\left\{\mathrm{T}^{\mathrm{n}}(\mathrm{x})\right\}$ is decreasing.

$$
\mathrm{d}(\mathrm{y}, \bar{x})=\lim _{n \rightarrow \infty}\left[(T)^{n k}(x), \bar{x}\right]=\lim _{n \rightarrow \infty} d\left[(T)^{n k+1}(x), \bar{x}\right]
$$

If $\alpha \neq 0$ then $\mathrm{y} \neq \bar{x}$ and so we have

$$
\begin{gathered}
\alpha=\mathrm{d}(\mathrm{y}, \bar{x})>\mathrm{d}[\mathrm{T}(\mathrm{y}), \mathrm{T}(\bar{x})]=d[T(y), \bar{x}] \\
=\lim _{n \rightarrow \infty} d\left[T^{n k}(x), \bar{x}\right]=d\left[T^{n k+1}(x), \bar{x}\right] \\
=\alpha
\end{gathered}
$$

Is a contraction.

Thus $\alpha=0$ and $\therefore \lim _{n \rightarrow \infty} T^{n}(x)=\bar{x}$.

\section{Further extension Of Banach Contraction Theorem}

Definition:-

4. Let $\mathrm{X}$ be a metric space, $\mathrm{A}$ function $\varphi: \mathrm{X} \longrightarrow \mathrm{R}$ is called

a) Lower semi continuous at $\mathrm{X}_{0} \in \mathrm{X}$ if $\lim _{x \rightarrow \mathrm{X} 0} \inf \varphi(x) \geq \varphi(\mathrm{X} 0)$

b) Upper semi continuous at $\mathrm{X}_{0} \in \mathrm{X}$ if $\lim _{x \rightarrow \mathrm{X} 0} \sup \varphi(x) \leq \varphi(\mathrm{X} 0)$

In general $\varphi$ is said to be lower semi-continuous (Upper semi-continuous

respectively) on $\mathrm{X}$ if for any sequence $\left\{\mathrm{x}_{\mathrm{n}}\right\}$ in $\mathrm{X}$ such that $\mathrm{X}_{\mathrm{n}} \rightarrow \mathrm{X}$ implies

$\therefore \lim _{n \rightarrow \infty} \inf \varphi(x n) \geq \varphi(x)$,

Example: -

$\therefore \lim _{n \rightarrow \infty} \sup \varphi(x n) \leq \varphi(\mathrm{x})$ respectively.

2. let $\varphi: \mathrm{R} \rightarrow \mathrm{R}$ be a function defined by $\varphi(x)=\left\{\begin{array}{r}-1, x<0 \\ 1, x \geq 0\end{array}\right.$

then $\varphi$ is upper semi continuous at $\mathrm{X}_{0}=0$ but not lower semi continuous.

Example: -

3. let $\varphi: \mathrm{R} \rightarrow \mathrm{R}$ be a function defined by $\varphi(x)=\left\{\begin{array}{r}-1, x \leq 0 \\ 1, x>0\end{array}\right.$

then $\varphi$ is lower semi continuous at $\mathrm{X}_{0}=0$ but not upper semi continuous.

\section{Theorem (Caristi's Theorem):-}

Caristi's develop contraction mapping principle in complete metric space for lower semi continuous function to find fixed point as above.

Let (x, d) be a complete metric space and $\mathrm{T}: \mathrm{X} \rightarrow \mathrm{X}$ be mapping (not necessarily continuous). Suppose there exist a lower semi continuous function $\varphi: \mathrm{X}$ $[0, \infty]$ such that $\mathrm{d}(\mathrm{x}, \mathrm{T}(\mathrm{x})) \leq \varphi(x)-\varphi[T(x)]$ for all $\mathrm{x} \in \mathrm{X}$, then $\mathrm{T}$ has a fixed point.

Here $\varphi$ is lower semi continuous and bounded below function of $\mathrm{X}$. 


\section{Caristi-Ekeland Principle}

This is one of the most interesting extensions of Banach contraction principle.

Let $\varphi: \mathrm{M} \longmapsto \mathrm{R}$ and assume that $\varphi$ is lower semi continuous.

i.e. for any sequence $\left\{X_{n}\right\}$ subset of $M$

if $\lim _{n \rightarrow \infty} x n=x$ and if $\lim _{n \rightarrow \infty} \varphi(x n)=r$ then $\varphi(x) \leq \mathrm{r}$

\section{Theorem:(Ekeland-1974):-}

Ekland developed Banach contraction mapping principle as follows

Let $(\mathrm{M}, \mathrm{d})$ be a complete metric space and $\varphi: \mathrm{M} \rightarrow \mathrm{R}^{+}$lower semi continuous such as

$$
\begin{gathered}
\mathrm{x} \leq \mathrm{y} \Leftrightarrow \mathrm{d}(\mathrm{x}, \mathrm{y}) \leq \varphi(x)-\varphi(y), \mathrm{x}, \mathrm{y} \in \mathrm{M} \\
\text { then }(\mathrm{M}, \leq) \text { has a maximal element } .
\end{gathered}
$$

\section{Theorem: (Caristi-1975):-}

Let $\mathrm{M}$ and $\varphi$ be as above, suppose $\mathrm{g}: \mathrm{M} \longrightarrow \mathrm{M}$ satisfies $\mathrm{d}(\mathrm{x}, \mathrm{g}(\mathrm{x})) \leq \varphi(x)-\varphi(g(x)), \mathrm{x} \in \mathrm{M}$ then $\mathrm{g}$ has affixed point.

The proof is based on discrete technique Zorn's lemma and axiom of choice applied to bronsted partial ordered. There are some trials of finding a pure metric proof of carsit's theorem.

\section{Conclusion:-}

In this paper we have presented the development of fixed point theorem in metric space.[1],[5] and [8].

\section{Acknowledgements:-}

The author are thankful to the referees for their valuable suggestions during the preparation of this paper.

\section{References:-}

1. Q. H. Ansari, Metric Space(Including Fixed Point Theory and Set-Valued Maps), Narosa Publishing House, 2010.

2. Pertr Kumlin, A note on fixed poin theory, TMA401/MAN6670 Functional Analysis 2003/2004.

3. Santosh kumar, A short Survey of the development of fixed point theory, Surveys in mathematics and its applications, Vol.8 (2013),91-101.

4. Andrzes Granas, James Dugundji, Fixed point theory, Springer Monographs in mathematics, QA329.9.D833 2003.

5. M.A.Khamsi, Introduction to metric fixed point theory.

6. Alok Asati, Amardeep Singh, C.L.Parihar, 127 years of Fixed Point Theory- "A Brief Survey of development of fixed point theory", Vol-04, issue 01, Jan/Feb-2013.

7. R.P. Agarwal, Donal O'regan, D.R.Sahu, Fixed Point theory for Lipchitzian-Type mappings with applications, Vol-06(2000) Springer dordrecht Heidelberg, Londan Newyork.

8. Saleh Almezel, Q.H.Ansari, M.A.Khamsi, Topics in fixed point theory, A Monograph on Fixed Point Theory.

9. D.R.Smart, Fixed Point Theory, Cambridge university press, 1974.

10. R.R.Goldberg, Methods Of Real Analysis, Oxford \& Ibh Publishing Company, New Delhi.

11. Noriko Mizoguchi, Wataru Takahashi, Fixed point thm for mul val map on comp metric space,JMAA141,177-188(1989). 